\title{
ВЛИЯНИЕ ТВЕРДОФАЗНЫХ ВКЛЮЧЕНИЙ НА ИЗОТОПНЫЙ СОСТАВ И СОДЕРЖАНИЕ ГЕЛИЯ В КЛИНОПИРОКСЕНЕ КОВДОРСКОГО МАССИВА
}

Сидоров М.Ю., Скиба В.И., Козлов Е.Н., Каменский И.Л.

${ }^{\prime}$ Геологический институт КНЦ РАН, Anamumbl, sidorov@geoksc.apatity.ru

\section{Введение, задачи и цели исследования}

На протяжении ряда лет в лаборатории геохронологии и изотопной геохимии ГИ КНЦ РАН в качестве внутрилабораторного твердофазного стандарта применялся клинопироксен из Ковдорского массива, предоставленный Е.Г. Балаганской. Использование термического метода экстракции гелия в зернах и «пудре Икорского» выявило несколько позиций нахождения гелия в указанном клинопироксене (рис. 1). Сравнение этих данных показало, что одна из позиций содержит около 50\% всего гелия вещества, в то время как содержание в них ${ }^{3} \mathrm{He}$ от общего содержания этого изотопа достигает двух третей. Более радиогенный состав гелия из второй позиции, максимум выделения которого происходит при полной деструкции вещества (плавлении), позволяет интерпретировать его как радиогенный гелий, образовавшийся in situ за счет распада $U$ и $T h$, в структуре минерала. Более мантийный гелий первой позиции рассматривается в качестве захваченного при кристаллизации. Традиционно в качестве основного механизма этого захвата рассматривается фиксация флюидной фазы в газово-жидких микровключениях, однако каких-либо специализированных исследований на этот предмет не проводилось. Первоначальная цель нашей работы заключалась в поиске включений и комплексном исследовании их методами термобарогеохимии.

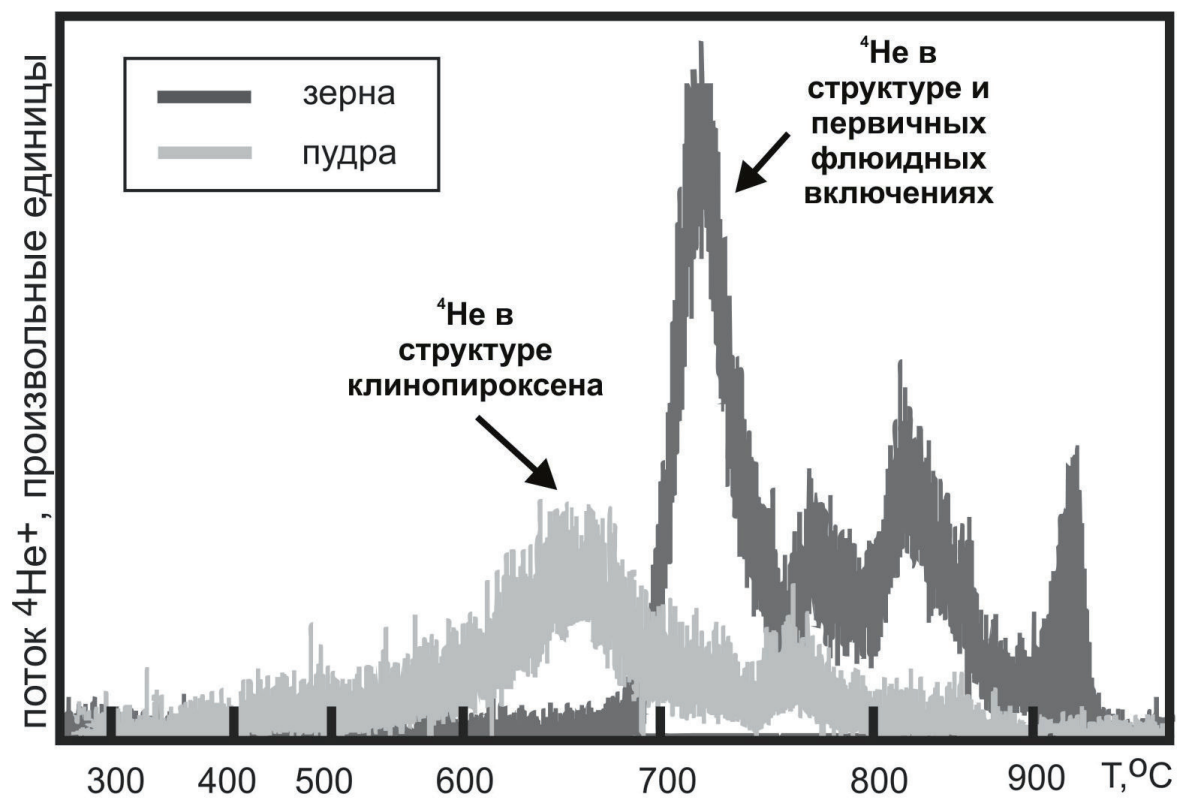

Рис. 1. Термограмма выделения гелия в зернах и «пудре».

\section{Образцы, методы исследования и результаты}

Монофракция клинопироксена из Ковдорского массива представлена буровато-зелеными кристаллами и их обломками, размер которых варьирует от 0,1 до 1,5 мм с преобладанием крупного размерного класса (рис. 2, а). Вместе с клинопироксеном в монофракции присутствует незначительное количество других минералов, среди которых чаще всего встречаются магнетит и флогопит.

Для поиска и диагностики флюидных включений был изготовлен искусственный аншлиф, содержащий около 160 кристаллов клинопироксена. Исследования проводились с помощью рамановского спектрометра Horiba Yvon HR 800, оборудованном конфокальным микроскопом Olympus ВX41 (РЦ «Геомодель», Научный парк СПбГУ, аналитик В.Н. Бочаров) по рекомендациям, указан- 


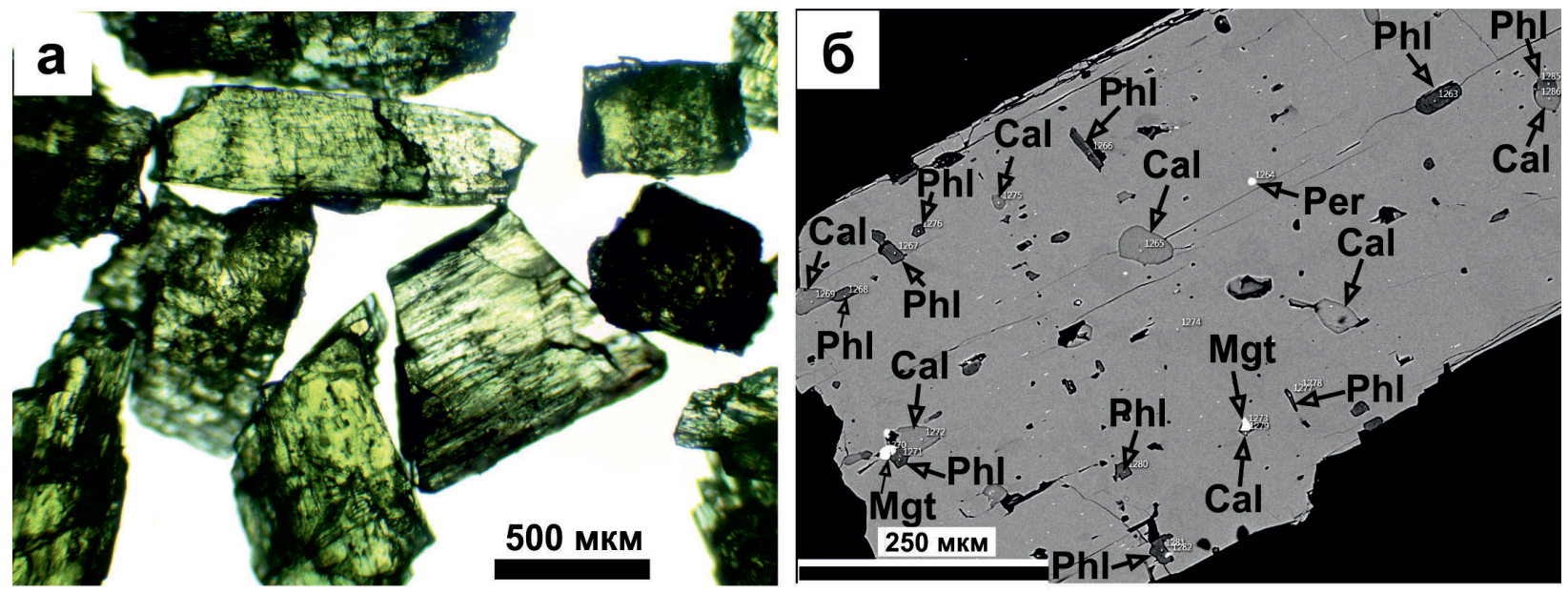

Рис. 2. Клинопироксен Ковдорского массива.

a - общий вид монофракции клинопироксена (оптическое изображение в проходящем свете); б - твердофазные минеральные включения в клинопироксене (изображение в обратно отраженных электронах). $\mathrm{Phl}$ - флогопит, Cal - кальцит, Mgt - магнетит, Per - перовскит.

ным в [3]. К нашему удивлению, собственно флюидные включения в исследованной выборке кристаллов отсутствуют! Вместо них были обнаружены многочисленные твердофазные минеральные включения, буквально переполняющие клинопироксен.

Для диагностики и определения химического состава минеральных включений в клинопироксене использовался электронный сканирующий микроскоп Hitachi S-3400 N, оборудованный энергодисперсионной приставкой для количественного анализа EDX-AzTec Energy 350 с комплектом стандартных образцов (РЦ «Геомодель», Научный парк СПбГУ, аналитик Н.С. Власенко). В ходе исследования в клинопироксене были диагностированы твердофазные минеральные включения магнетита, кальцита, апатита, флогопита, перовскита и их срастания (рис. 2, б). Объемное содержание минеральных включений в клинопироксене составляет 10-15\%.

Специфика минерального состава включений, обладающих резко отличной магнитной восприимчивостью, позволила для грубого экспрессного разделения вещества использовать универсальный постоянный магнит А.Я. Сочнева модели С-5. Разделение проводилось на сильномагнитную и слабомагнитную фракции и немагнитный остаток (В.И. Басалаева, ГИ КНЦ РАН, Апатиты). В сильномагнитной фракции клинопироксен присутствует в незначительных количествах, в целом она отвечает составу темноцветных включений с преобладанием магнетита. Слабомагнитная фракция представлена клинопироксеном и флогопитом. Немагнитная фракция состоит из обломков клинопироксена с незначительной примесью других минералов и больше других фракций соответствует исходному клинопироксену (рис. 3).
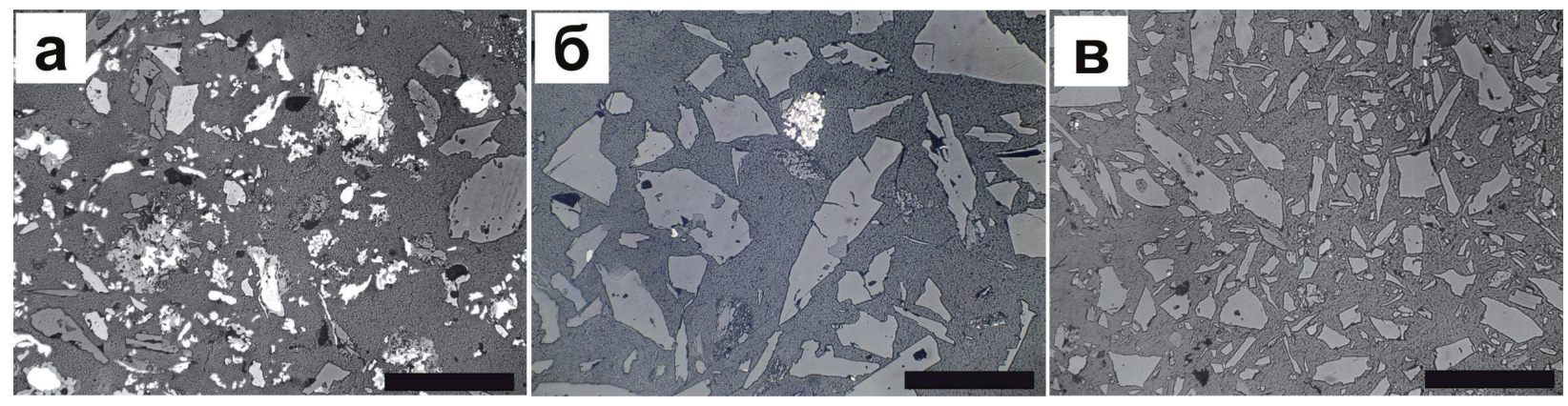

Рис. 3. Выделенные по магнитным свойствам фракции.

a - магнитная, б - слабомагнитная, в - немагнитный остаток. Изображения в отраженном свете. Линейный масштаб 250 мкм. 
Размер минеральных обломков в выделенных фракциях значительно меньше, чем модальный размер ранее исследованного исходного клинопироксена и варьирует от 0.01 до 0.25 мм, причем магнитная и немагнитная фракции сложены самыми мелкими обломками. В исходной фракции клинопироксена и отсепарированных фракциях для выделения гелия применялся метод дробления в вакуумированных стеклянных ампулах [1]. Анализы производились на масс-спектрометре МИ-1201. В дополнение к полученным результатам (таблица) приведены данные по гелию в исходном пироксене, экстрагированному как дроблением, так и плавлением. Отметим, что именно в исходной монофракции клинопироксена установлены самые высокие содержания и отношения изотопов гелия. Из трех фракций самое низкое отношение ${ }^{3} \mathrm{He} /{ }^{4} \mathrm{He}$ оказалось в магнитной фракции, значительно выше (в 1.5 раза) - в слабомагнитной, а самое высокое, близкое к исходному клинопироксену, - в немагнитной. Для всех выделенных фракций получено меньшее содержание изотопов гелия по сравнению с исходной монофракцией клинопироксена.

Таблица. Результаты изотопных анализов гелия в различных по магнитным свойствам фракциях из клинопироксена Ковдорского массива.

\begin{tabular}{|c|c|c|c|c|c|c|c|}
\hline \multirow{2}{*}{ Образец } & \multirow{2}{*}{ Навеска, г } & \multirow{2}{*}{ Фракция, мм } & \multirow{2}{*}{$\begin{array}{c}\text { Метод } \\
\text { экстракции }\end{array}$} & \multirow{2}{*}{$\begin{array}{c}{ }^{4} \mathrm{He}^{4} \times 10^{-6}, \\
\mathrm{CM}^{3} / \Gamma\end{array}$} & \multicolumn{2}{|c|}{$\left({ }^{3} \mathrm{He} /{ }^{4} \mathrm{He}\right)$} & \multirow{2}{*}{$\begin{array}{c}{ }^{3} \mathrm{He} \times 10^{-10}, \\
\mathrm{Cm}^{3} / \Gamma\end{array}$} \\
\hline & & & & & $\times 10^{-6}$ & $\mathrm{R}$ & \\
\hline $\begin{array}{l}\text { Магнитная } \\
\text { фракция }\end{array}$ & 0.1 & $0.01-0.25$ & дробление & 5.7 & 8.8 & 6.29 & 0.50 \\
\hline $\begin{array}{l}\text { Слабомагнит- } \\
\text { ная фракция }\end{array}$ & 0.1 & $0.01-0.25$ & дробление & 7.7 & 12.2 & 8.71 & 0.94 \\
\hline $\begin{array}{l}\text { Немагнитная } \\
\text { фракция }\end{array}$ & 0.2 & $0.01-0.25$ & дробление & 5.95 & 13.7 & 9.79 & 0.82 \\
\hline \multirow{5}{*}{$\begin{array}{l}\text { Исходный } \\
\text { клинопироксен }\end{array}$} & 2.0 & $0.25-0.63$ & дробление & 12.1 & 16.3 & 11.64 & 1.97 \\
\hline & 2.0 & $0.25-0.63$ & дробление & 12.3 & 15.9 & 11.36 & 1.96 \\
\hline & 0.4 & $0.25-0.63$ & дробление & 18.3 & 15.01 & 10.72 & 2.75 \\
\hline & 2.0 & $0.25-0.63$ & плавление & 37 & 8.31 & 0.23 & 3.08 \\
\hline & 2.0 & $0.25-0.63$ & плавление & 40 & 7.6 & 0.19 & 3.04 \\
\hline
\end{tabular}

Примечание: $\mathrm{R}=\left({ }^{3} \mathrm{He} /{ }^{4} \mathrm{He}\right) / \mathrm{R}_{\mathrm{a}}$, где $\mathrm{R}_{\mathrm{a}}-$ соотношение изотопов гелия в атмосферном воздухе, равное $1,4 \times 10^{-6}$.

\section{Обсуждение результатов и выводы}

Специальные исследования в значительной выборке кристаллов клинопироксена Ковдорского массива не выявили присутствие в них флюидных микровключений, что оставляет открытым вопрос о местонахождении захваченного гелия в этом минерале.

Значительная разница в содержаниях и отношениях изотопов гелия в исходном клинопироксене и выделенных фракциях (рис. 4) объясняется нами меньшими размерами минеральных обломков во фракциях. Напомним, что ранее исследовавшийся исходный клинопироксен в силу некоторых обстоятельств был существенно более крупнозернистым, чем тот, что пошел на магнитную сепарацию. Наблюдающаяся устойчивая тенденция к уменьшению содержания гелия в клинопироксене по мере снижения размерности зерен от исходного пироксена к отсепарированным фракциям, вероятней всего, связана с частичной физической потерей гелия из ранее указанной первой позиции («захваченного» гелия) в ходе измельчения вещества при пробоподготовке. Это объясняет и некоторое смещение отношения ${ }^{3} \mathrm{He} /{ }^{4} \mathrm{He}$ от исходного клинопироксена к пироксену из немагнитной и слабомагнитной фракции, что делает вопрос о структурной позиции гелия еще более острым.

$\mathrm{C}$ точки зрения отношения ${ }^{3} \mathrm{He} /{ }^{4} \mathrm{He}$ аномально низким (в 1.5-2 раза меньшими, чем в прочих анализах) оказался изотопный состав гелия в магнитной фракции, состоящей преимущественно из магнетита и флогопита - основных минералов включений. Отметим, что сходный результат был ранее получен при изучении изотопии гелия в магнетите и клинопироксене из мелилит-оливинкальцитового пегматита Ковдорского массива [2]. Таким образом, сами включения в клинопироксене являются обособленным источником более радиогенного гелия.

Проведенные нами исследования показывают, что для корректной интерпретации данных по изотопии гелия необходимо проведение предварительного минералогического и химического изучения образцов. Прежде всего, это поиск и диагностика флюидных включений в прозрачных мине- 


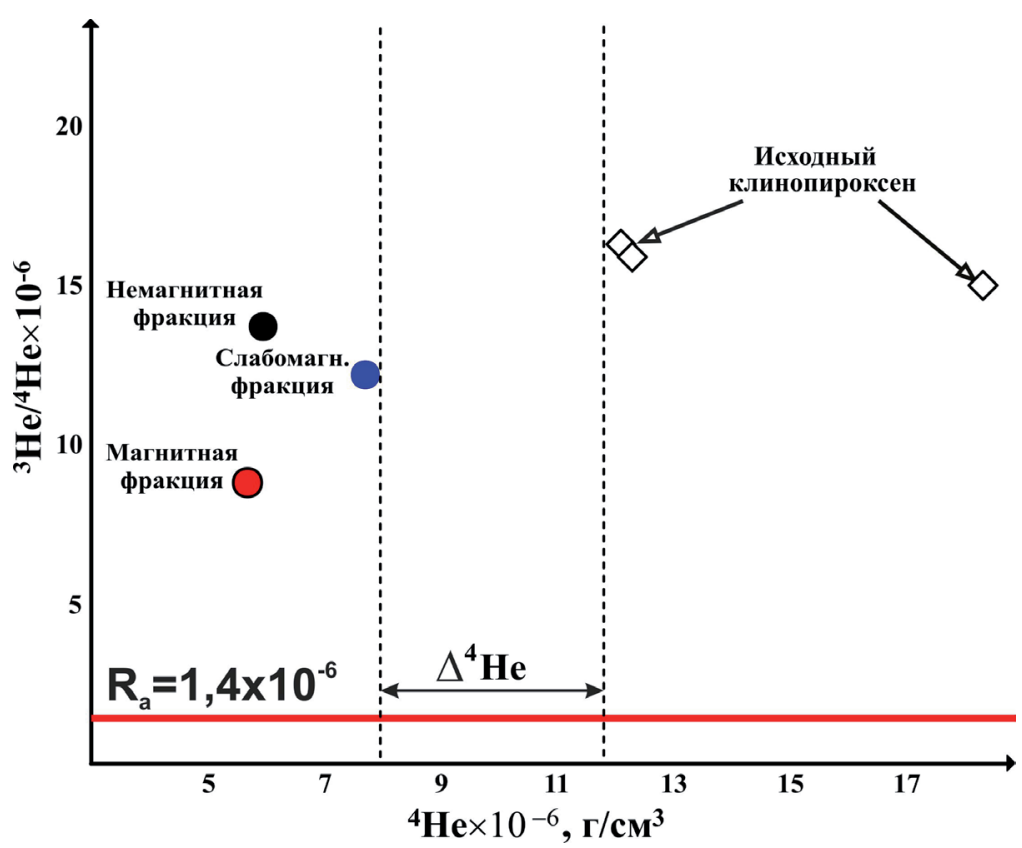

Рис. 4. Отношения изотопов гелия и концентрации ${ }^{4} \mathrm{He}$ в клинопироксене и различных по магнитным свойствам фракциях. $\mathrm{R}_{\mathrm{a}}$ - соотношение изотопов гелия в атмосферном воздухе, $\Delta^{4} \mathrm{He}-$ потери гелия при дроблении.

ралах с помощью рамановской спектроскопии как наиболее экспрессного метода. При выявлении заметного количества твердофазных включений в исследуемом минерале, необходимо попытаться разделить фазы различными методами сепарации (магнитная и электромагнитная сепарация, разделение в тяжелых жидкостях и др.) и провести изотопные исследования в выделенных фракциях. Для оценки вклада радиогенных изотопов гелия в выявленных отношениях ${ }^{3} \mathrm{He} /{ }^{4} \mathrm{He}$ необходимо провести химический анализ фракций на литий, уран и торий.

\section{Благодарности}

Авторы выражают искреннюю благодарность В.И. Басалаевой (ГИ КНЦ РАН, Апатиты), а также В.Н. Бочарову и Н.С. Власенко (РЦ «Геомодель», Санкт-Петербург) за помощь в проведении аналитических работ.

Работа выполнена в Геологическом институте Кольского научного центра РАН в рамках государственного заказа № 0231-2015-0009.

\section{Литература}

1. Икорский С.В., Каменский И.Л. Метод дробления горных пород и минералов горных пород и минералов в стеклянных ампулах при изотопных исследованиях благородных газов // Тез. докл. XV Симпозиума по геохимии изотопов им. академика А.П. Виноградова. Москва. 1998. С. 115.

2. Каменский И.Л., Икорский С.В., Каулина Т.В. Диагностика изотопной генетической метки ${ }^{3} \mathrm{He} /{ }^{4} \mathrm{He}$ на примере минералов мелилит-оливин-кальцитового пегматита в оливинитах Ковдорского массива (Кольский полуостров) // Вестник ИГ КомиНЦ УрО РАН. 2014. № 12. С. 3-7.

3. Frezzotti M.L., Tecce F., Casagli A. Raman spectroscopy for fluid inclusion analysis // Journal of Geochemical Exploration. 2012. V. 112. P. 1-20. 